Tropical Journal of Pharmaceutical Research September 2021; 20 (9): 1999-2004

ISSN: $1596-5996$ (print); 1596-9827 (electronic) (C) Pharmacotherapy Group, Faculty of Pharmacy, University of Benin, Benin City, 300001 Nigeria

\title{
Efficacy and prognosis following combined cinepazaide maleate/nimodipine therapy in cerebral vasospasm patients after hemorrhage
}

\author{
Tao Wu $\mathbf{~}^{1}$, Fangshu $\mathrm{Chen}^{2}$, Hanyan $\mathrm{Xiao}^{3}$, Tianying $\mathrm{Xu}^{3 *}$ \\ ${ }^{1}$ Department of Neurosurgery, Linyi Central Hospital, Linyi 276400, Shandong Province, ${ }^{2}$ Department of Neuro Intervention, \\ Zhangqiu District People's Hospital, Jinan 250200, Shandong Province, ${ }^{3}$ Department of Neurology, The Second Affiliated \\ Hospital of Mudanjiang Medical College, Mudanjiang 157010, Heilongjiang Province, China
}

*For correspondence: Email: tx3m2c@163.com; Tel: +92-51-90643223

Sent for review: 1 May 2021

Revised accepted: 22 August 2021

\begin{abstract}
Purpose: To investigate the efficacy and prognosis following treatment of cerebral vasospasm (CVS) patients with a combination of cinnarizide maleate and nimodipine after subarachnoid hemorrhage (SAH).

Methods: Eighty-eight patients with CVS after SAH were selected and divided into control group (CG) and study group (EG), each with 44 patients $(n=44)$. Patients in CG were treated with intravenous infusion of cinnarizide maleate, while those in EG received intravenous infusion of cinnarizide maleate together, and their clinical efficacy and prognosis were compared.

Results: Compared with CG, total treatment effectiveness (response) in EG was significantly higher, while levels of inflammatory factors were lower $(p<0.05)$. Serum protein levels of S100 $\beta$ and $E T-1$, and MCA blood flow velocity in EG were notably lower $(p<0.05)$, but GCS scores were higher compared with CG $(p<0.05)$. The NIHSS scores were lower and BI indices were higher in EG than in CG $(p<0.05)$

Conclusion: Treatment of CVS patients after SAH using a combination of cinnarizide maleate and nimodipine effectively reduces the levels of inflammatory factors, improves quality of prognosis, and relieves symptoms of CVS, when compared with administration of cinnarizide maleate only. Therefore, the combination treatment is recommended for the management of CVS after SAH.
\end{abstract}

Keywords: Cinnarizide maleate, Nimodipine, Cerebral vasospasm (CVS), Subarachnoid hemorrhage $(S A H)$

\begin{abstract}
This is an Open Access article that uses a funding model which does not charge readers or their institutions for access and distributed under the terms of the Creative Commons Attribution License (http://creativecommons.org/licenses/by/4.0) and the Budapest Open Access Initiative (http://www.budapestopenaccessinitiative.org/read), which permit unrestricted use, distribution, and reproduction in any medium, provided the original work is properly credited.

Tropical Journal of Pharmaceutical Research is indexed by Science Citation Index (SciSearch), Scopus, International Pharmaceutical Abstract, Chemical Abstracts, Embase, Index Copernicus, EBSCO, African Index Medicus, JournalSeek, Journal Citation Reports/Science Edition, Directory of Open Access Journals (DOAJ), African Journal Online, Bioline International, Open-J-Gate and Pharmacy Abstracts
\end{abstract}

\section{INTRODUCTION}

Subarachnoid hemorrhage (SAH) results from cerebral stroke in which blood from ruptured cerebral blood vessels flows into subarachnoid space, resulting in cerebral vasospasm (CVS).
The disease affects mostly middle-aged and elderly populations within the age range of 40 to 60 years old, and it accounts for $10 \%$ of all strokes in China. Cerebral vasospasm (CVS) is a common complication of $\mathrm{SAH}$, and its incidence in patients with SAH may reach up to 
$90 \%$ [1-3]. Failure to intensify therapeutic intervention at the onset of the disease may predispose the patients to severe cerebral ischemia or ischemic brain injury, thereby aggravating their conditions or even endangering their lives.

Nimodipine, a calcium ion antagonist, effectively improves blood circulation in the recovery phase of acute cerebrovascular diseases. Studies have shown that nimodipine produces significant clinical efficacy in the treatment of CVS after $\mathrm{SAH}$ caused by various factors; a finding which has been widely applied in clinical practice [4-6]. Cinnarizide maleate is a calcium channel blocker that relaxes vascular smooth muscles and dilates cerebral, peripheral as well as coronary vessels by preventing transmembrane entry of calcium ions into the vascular smooth muscle cells. This relieves vasospasm, reduces vascular resistance and increases blood flow $[7,8]$. Nimodipine and cinnarizide are clinically used for the treatment of cerebrovascular diseases. However, in clinical practice, not much is known about the effect of combination of these two drugs on outcomes in the treatment of CVS after SAH. The present study was carried out to investigate the clinical efficacy and prognosis associated with application of cinnarizide maleate in combination with nimodipine for treatment of CVS after SAH.

\section{METHODS}

\section{Profile of patients}

Eighty-eight patients with CVS after SAH, who were admitted to our hospital from January 2017 to December 2018, were selected as study subjects. They were randomized into control group (CG) and study group (EG) based on tossing of a coin, each with 44 patients. CG had 26 males and 18 females, aged from 33 to 72 years (mean age $=53.3 \pm 4.5$ years), while EG had 28 males and 16 females aged 30 to 73 years, with mean age of $52.1 \pm 4.6$ years. No statistical differences in the profiles of the patients were observed between EG and CG ( $p$ $>0.05)$.

\section{Inclusion criteria}

Patients in the following categories were included in the study: those who met the clinical diagnostic criteria for CVS after SAH according to the Chinese guidelines for diagnosis and treatment of SAH (2015) after diagnosis using CT and ultrasonic testing, patients aged 18 years and above, and patients who had complete clinical medical records.

\section{Exclusion criteria}

Patients who had other organ and tissue lesions e.g., lesions in brain, heart, kidneys, and liver; those with history of cerebral infarction or intracranial tumors, patients with metabolic diseases, and those who had mental and cognitive disorders were excluded from the study. In addition, patients who refused to cooperate with the investigators were excluded.

This study was approved by the Ethics Committee of Linyi Central Hospital (approval no. 20161184). The patients and their family members were duly informed about the purpose of the study and the protocols involved, and they signed informed consent. The study followed international guidelines for human studies.

\section{Treatments}

Following doctors' advice, all the patients were subjected to several examinations after admission, and were positively coordinated with the treatment. After surgery, patients in CG were treated with intravenous infusion of $500 \mathrm{~mL}$ of $0.9 \%$ sodium chloride containing $320 \mathrm{mg}$ of cinnarizide maleate (Beijing Sihuan Pharmaceutical Co. Ltd; specification: $2 \mathrm{~mL}, 80$ mg/bottle; National Medical Products Administration (approval no. H20020125) [9,10].

In EG, the patients were treated with intravenous administration of nimodipine, in addition to intravenous infusion of cinnarizide as CG. The intravenous pumping of nimodipine (Shandong Fangming Pharmaceutical Group Co. Ltd; specification: $20 \mathrm{~mL}, 4 \mathrm{mg} / \mathrm{vial}$; National Medical Products Administration (approval no. $\mathrm{H} 20033549$ ) was carried out via a microinjection pump at a flow rate of $2.5-5 \mathrm{ml} / \mathrm{h}$. After the medication regimen was adjusted according to conditions of the patients, nimodipine tablets (Chiatai Qingchunbao Pharmaceutical Co. Ltd; specification: $20 \mathrm{mg} \times 20$ tablets; National Medical Products Administration approval no.: $\mathrm{H} 33022285)$ were administered orally at $1-2$ weeks after treatment, at a dose of $60 \mathrm{mg}$, three times daily for 3 weeks.

\section{Treatment indices}

The prognosis of patients in both treatment groups was determined in terms treatment efficacy which was categorized into three levels: ineffective, effective and markedly effective. Treatment was deemed markedly effective if clinical adverse symptoms disappeared, and results of CT examination showed no abnormality. If clinical conditions were improved, 
the treatment effect was classified as effective. However, the treatment effect was classified as ineffective if there were no improvements in the conditions of the patients, or if the conditions became aggravated. Total treatment effectiveness was calculated as indicated below:

$\operatorname{TTE}(\%)=\underline{(M E+E) / T \times 100}$

where $T T E=$ total treatment effectiveness; $M E=$ markedly effective cases; $E=$ effective cases, and $T=$ Total number of patients

The levels of inflammatory factors, serum protein levels of S100 $\beta$ and ET-1, and velocity of MCA blood flow, were measured before and after treatment.

Glasgow coma scale (GCS) was used to evaluate the physical status before and after treatment in three aspects of eye-opening response, verbal response and motor response. Higher scores indicated better physical status. The National Institute of Health stroke scale (NIHSS) was applied to evaluate the neurologic function before and after treatment. In this scale, lower scores indicated better neural functional recovery. In addition, the Barthel index $(\mathrm{BI})$ was adopted to evaluate capacity of patients for selfcare before and after treatment. Higher scores indicated better self-care ability.

\section{Statistical analysis}

The SPSS 20.0 software was used for data processing, while GraphPad Prism 7 (GraphPad Software, San Diego, USA) was used for graphics. Measurement data were compared between the two groups using $t$-test, while enumeration data were compared using Chi square test and normality test. Differences were considered statistically significant at $p<0.05$.

\section{RESULTS}

\section{Therapeutic effect}

Total treatment effectiveness was markedly higher in EG than in CG $(p<0.05)$, see Table 1.

\section{Levels of inflammatory factors}

After treatment, the levels of inflammatory factors in both groups obviously decreased, but the levels of inflammatory factors in EG were markedly lower compared with CG $(p<0.05)$, see Table 2.

\section{Serum levels of S100 $\beta$ protein and ET-1, MCA blood flow velocity}

After treatment, serum levels of $S 100 \beta$ protein and ET-1 as well as MCA blood flow velocity in both groups notably decreased, with lower levels and blood flow velocity in EG than CG after treatment $(p<0.05)$.

Table 1: Therapeutic effect of the two groups [n (\%)]

\begin{tabular}{lcccc}
\hline Group & Ineffective & Effective & $\begin{array}{c}\text { Markedly } \\
\text { effective }\end{array}$ & $\begin{array}{c}\text { Total } \\
\text { effectiveness }\end{array}$ \\
\hline CG $(n=44)$ & $11(25.00)$ & $15(34.09)$ & $18(40.91)$ & $33(75.00)$ \\
EG $(n=44)$ & $2(4.55)$ & $12(27.27)$ & $30(68.18)$ & $42(95.45)$ \\
$X^{2}$ & & & & 7.3108 \\
$P$-value & & & & 0.007 \\
\hline
\end{tabular}

Table 2: Comparison of levels of inflammatory factors before and after treatment

\begin{tabular}{lcccc}
\hline Group & & IL-6 (ng/L) & TNF- $\alpha$ (ng/L) & CPA (mg/L) \\
\hline CG $(\mathrm{n}=44)$ & Before & $12.87 \pm 2.88$ & $47.36 \pm 8.25$ & $53.01 \pm 5.87$ \\
& treatment & & & \\
& After & $9.85 \pm 2.39$ & $40.73 \pm 7.51$ & $40.70 \pm 5.47$ \\
$X^{2}$ & treatment & & & \\
$P$ & & 5.3526 & 3.9420 & 10.1769 \\
EG $(\mathrm{n}=44)$ & 0.000 & 0.0002 & 0.000 \\
& Before & $12.75 \pm 2.91$ & $47.21 \pm 8.23$ & $52.95 \pm 5.89$ \\
& treatment & & \\
$X^{2}$ & After & $8.06 \pm 2.26^{*}$ & $35.64 \pm 6.43^{*}$ & $23.88 \pm 4.37^{*}$ \\
$P$-value & treatment & & & \\
${ }^{*} P<0.05$, levels of inflammatory factors after treatment vs CG values & 0.000 & 26.2921 \\
& & 0.4434 &
\end{tabular}


Table 3: Comparison of levels of serum S100 $\beta$ protein and ET-1 as well as MCA blood flow velocity before and after treatment

\begin{tabular}{|c|c|c|c|c|}
\hline Group & & S100 $\beta$ protein $(\mu \mathrm{g} / \mathrm{L})$ & ET-1 (pg/mL) & MCA (cm/sec) \\
\hline \multirow[t]{2}{*}{ CG $(n=44)$} & $\begin{array}{c}\text { Before } \\
\text { treatment }\end{array}$ & $0.27 \pm 0.06$ & $88.16 \pm 12.31$ & $104.23 \pm 25.29$ \\
\hline & $\begin{array}{c}\text { After } \\
\text { treatment }\end{array}$ & $0.20 \pm 0.05$ & $74.84 \pm 8.27$ & $90.42 \pm 20.89$ \\
\hline$x^{2}$ & & 5.9451 & 5.9578 & 2.7927 \\
\hline$\hat{P}$ & & 0.000 & 0.000 & 0.0064 \\
\hline \multirow[t]{2}{*}{$E G(n=44)$} & $\begin{array}{c}\text { Before } \\
\text { treatment }\end{array}$ & $0.26 \pm 0.08$ & $87.65 \pm 12.24$ & $103.65 \pm 26.23$ \\
\hline & $\begin{array}{c}\text { After } \\
\text { treatment }\end{array}$ & $0.15 \pm 0.04^{*}$ & $70.22 \pm 8.45^{\star}$ & $78.58 \pm 18.33^{*}$ \\
\hline $\begin{array}{l}\mathrm{X}^{2} \\
P \text {-value }\end{array}$ & & $\begin{array}{c}8.1578 \\
0.000\end{array}$ & $\begin{array}{c}9.7786 \\
0.000\end{array}$ & $\begin{array}{c}5.1967 \\
0.000\end{array}$ \\
\hline
\end{tabular}

\section{Comparison of GCS scores between the two groups}

As shown in Figure 1, GCS scores in both after treatment were markedly higher than the corresponding values before treatment. However, the post-treatment GCS scores in EG exceeded those in CG $(p<0.05)$.

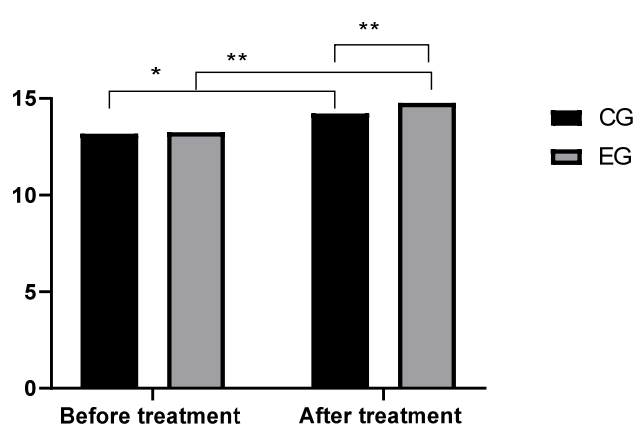

Figure 1: Comparison of GCS scores. Values are expressed as mean \pm SD. ${ }^{*} P=0.0005$, GCS scores in CG before treatment vs score after treatment $(t=$ 3.6454); ${ }^{* *} p<0.001$, GCS score in EG before treatment vs score after treatment $(t=5.1493) ;{ }^{* * *} p=$ 0.0077 , comparison of GCS scores between EG and CG after treatment $(t=2.7280)$

\section{NIHSS scores}

The NIHSS scores in both groups after treatment notably decreased, but the NIHSS score in EG after treatment was markedly lower than that in CG. See Figure 2.

\section{Bl index}

The values of $\mathrm{BI}$ indexes in both groups after treatment increased, but the values of $\mathrm{BI}$ indices after treatment in EG were markedly higher than those in CG, which were presented in Figure 3.

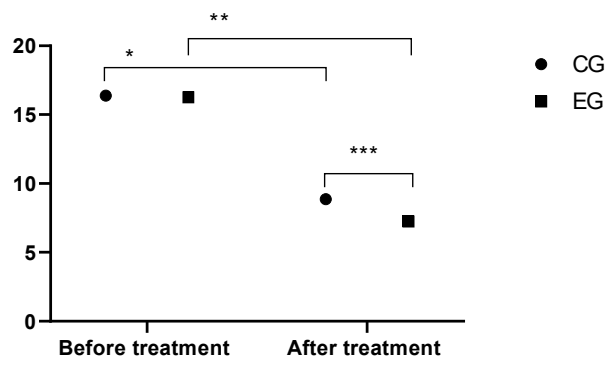

Figure 2: Comparison of NIHSS scores. Values are presented as mean \pm SD. ${ }^{*} P<0.001$, NIHSS score in CG before treatment vs score after treatment $(t=$ 12.5333); ${ }^{* *} P<0.001$, NIHSS score in EG before treatment vs score after treatment $(\mathrm{t}=13.7997) ;{ }^{* * *} p=$ 0.0028 , NIHSS scores of the two groups after treatment $(t=3.0812)$

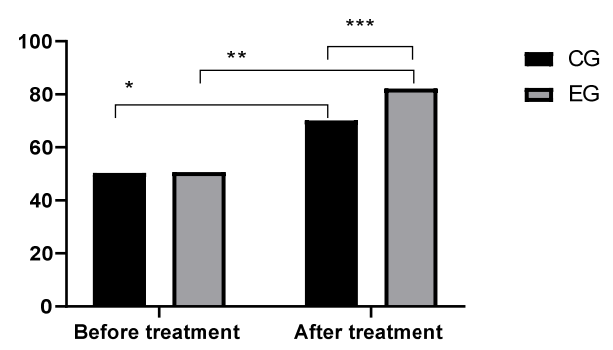

Figure 3: $\mathrm{BI}$ index values of the two groups. Values are expressed as mean $\pm \mathrm{SD}$ ). ${ }^{*} P<0.001$, BI index values in CG before treatment vs values after treatment $(t=10.7649) ;{ }^{* *} P<0.001$, values of $\mathrm{BI}$ indices in EG before treatment vs corresponding values after treatment $(t=16.3346) ;{ }^{* * *} P<0.001$, values of $\mathrm{BI}$ indices of the two groups after treatment $(t=5.7949)$

\section{DISCUSSION}

Cerebral vasospasm (CVS) after subarachnoid hemorrhage (SAH) manifests as smooth muscle contraction due to massive release of calcium 
ions from the cellular calcium stores and influx of calcium ions from vascular smooth muscle cells. The affected patients present with cerebral ischemia as a result of cerebral hemorrhage which may lead to increased intracranial pressure. If the patient does not receive timely treatment, the situation may lead to aggravated brain tissue damage. Generally, before clinical treatment, proper blood supply is required so as to avoid irreversible damage due to cerebral ischemia [11-13].

Nimodipine is a calcium antagonist with strong lipo-solubility [14]. Thus, it can cross the bloodbrain barrier and act selectively on cerebral blood vessels, leading to reduction of concentration of calcium ions, thereby ensuring proper development of nerve cells. Moreover, nimodipine selectively inhibits smooth muscle contraction in cerebral blood vessels and effectively relieves CVS. Cinnarizide maleate is a novel calcium channel antagonist which blocks the entry of calcium ions into smooth muscle cells, dilates blood vessels at the lesion sites, increases blood flow volume, and improves cerebral metabolism. In addition, cinnarizide reduces the levels of inflammatory factors by inhibiting platelet aggregation [15-17].

The results of this study showed that compared with CG, total treatment effectiveness (response) in EG was markedly higher, while levels of inflammatory factors were markedly lower $(p<$ 0.05). Serum protein levels of $S 100 \beta$ and ET-1, and MCA blood flow velocity in EG were notably lower $(p<0.05)$. The $S 100 \beta$ protein is a brain injury-specific protein in the nervous system. It enhances the development of nervous system and accelerates the proliferation and differentiation of nerve cells. Besides, when intracranial hemorrhage occurs, the expression of $\mathbf{S 1 0 0} \beta$ protein is abnormally elevated. This spills over large number of damaged cells, inducing inflammatory factors and accelerating neural cells apoptosis. Compared with CG, EG achieved markedly higher GCS scores $(p<$ $0.05)$, notably lower NIHSS scores $(p<0.05)$ and obviously higher $\mathrm{BI}$ indexes $(p<0.05)$.

These results indicate that combined treatment with cinnarizide maleate and nimodipine produces marked neuroprotective effect on patients. This finding is consistent with those reported earlier, in which the application of nimodipine for treatment of CVS after SAH effectively improved blood flow velocity of the cerebral artery in patients and reduced the incidence of complications [18]. Moreover, nimodipine had positive effect on prognosis, indicating that the application of cinnarizide maleate and nimodipine results in significant therapeutic effect.

\section{CONCLUSION}

The application of cinnarizide maleate in combination with nimodipine for the treatment of CVS after SAH effectively reduced the levels of inflammatory factors, improved prognosis, and relieved the symptoms of cerebral vasospasm in patients. The combination treatment produced significant clinical efficacy. Therefore, it merits clinical popularization in the treatment of CVS after SAH.

\section{DECLARATIONS}

\section{Conflict of interest}

No conflict of interest is associated with this work.

\section{Contribution of authors}

We declare that this work was done by the authors named in this article and all liabilities pertaining to claims relating to the content of this article will be borne by the authors. TW conceived and designed the study, and drafted the manuscript. FC and HX collected, analyzed and interpreted the experimental data. TX revised the manuscript for important intellectual content. All authors read and approved the final manuscript.

\section{Open Access}

This is an Open Access article that uses a funding model which does not charge readers or their institutions for access and distributed under the terms of the Creative Commons Attribution License (http://creativecommons.org/licenses/by/ 4.0) and the Budapest Open Access Initiative (http://www.budapestopenaccessinitiative.org/rea d), which permit unrestricted use, distribution, and reproduction in any medium, provided the original work is properly credited.

\section{REFERENCES}

1. Al-Mufti F, Amuluru K, Lander M, Mathew M, El-Ghanem M, Nuoman R, Park S, Patel V, Singh IP, Gupta G, et al. Low Glasgow Coma Score in Traumatic Intracranial Hemorrhage Predicts Development of Cerebral Vasospasm. World Neurosurg. 2018 Dec;120: e68-e71.

2. Darsaut TE, Derksen C, Farzin B, Keough MB, Fahed R, Boisseau W, Letourneau-Guillon L, Januel AC, Weill A, Roy $D$, et al. Reliability of the Diagnosis of Cerebral

Trop J Pharm Res, September 2021; 20(9): 2003 
Vasospasm Using Catheter Cerebral Angiography: A Systematic Review and Inter- and Intraobserver Study. AJNR Am J Neuroradiol. 2021 Mar;42(3):501-507.

3. Chaudhry SR, Güresir A, Stoffel-Wagner B, Fimmers R, Kinfe TM, Dietrich $D$, Lamprecht $A$, Vatter $H$, Güresir $E$, Muhammad S. Systemic High-Mobility Group Box-1: A Novel Predictive Biomarker for Cerebral Vasospasm in Aneurysmal Subarachnoid Hemorrhage. Crit Care Med. 2018 Nov;46(11): e1023-e1028.

4. Liu X, Zhao N, Zeng $K$, Xiao $P$, Sheng $P$, Luo X, Wang $Y$. Effects of nimodipine combined with betahistine on CRP and other inflammatory cytokines and vascular endothelial function in patients with hypertensive cerebral vasospasm. Clin Hemorheol Microcirc. 2020;75(3):279-289.

5. Adami D, Berkefeld J, Platz J, Konczalla J, Pfeilschifter $W$, Weidauer $S$, Wagner $M$. Complication rate of intraarterial treatment of severe cerebral vasospasm after subarachnoid hemorrhage with nimodipine and percutaneous trans/uminal balloon angioplasty: Worth the risk? J Neuroradiol. 2019 Feb;46(1):15-24.

6. Pal'a A, Schneider M, Brand C, Pedro MT, Özpeynirci $Y$, Schmitz B, Wirtz CR, Kapapa T, König R, Braun M. The evolution of invasive cerebral vasospasm treatment in patients with spontaneous subarachnoid hemorrhage and delayed cerebral ischemia-continuous selective intracarotid nimodipine therapy in awake patients without sedation. Neurosurg Rev. 2019 Jun;42(2):463469.

7. Cai Z, Zhang $H$, Song $H$, Piao $Y$, Zhang $X$. Edaravone combined with cinepazide maleate on neurocyte autophagy and neurological function in rats with subarachnoid hemorrhage. Exp Ther Med. 2020 Jan;19(1):646-650.

8. Ni J, Chen H, Chen G, Ji Y, Yi F, Zhang Z, Yang Y, Wu J, Cai $X$, Shao $B$, et al. Efficacy and safety of cinepazide maleate injection in patients with acute ischemic stroke: a multicenter, randomized, double-blind, placebocontrolled trial. BMC Neurol. 2020 Jul 14;20(1):282.

9. A, Diwan A, Thabet HK, Imran M. Synthesis of some pyridazine derivatives as antioxidants and antimicrobial agents. Trop J Pharm Res 2019; 18(12):2633-2641

10. Ansari MA, lqubal A, Ekbbal R, Haque SE. Effects of nimodipine, vinpocetine and their combination on isoproterenol-induced myocardial infarction in rats. Biomed Pharmacother 2019; 109: 1372-1380.
11. loannidis I, Nasis N, Agianniotaki A, Katsouda E, Andreou A. Reversible cerebral vasoconstriction syndrome: Treatment with multiple sessions of intraarterial nimodipine and angioplasty. Interv Neuroradiol 2012; 18: 297-302.

12. Kieninger M, Flessa J, Lindenberg $N$, Bele S, Redel A, Schneiker A, Schuierer G, Wendl C, Graf B, Silbereisen $V$. Side Effects of Long-Term Continuous Intra-arterial Nimodipine Infusion in Patients with Severe Refractory Cerebral Vasospasm after Subarachnoid Hemorrhage. Neurocrit Care. 2018 Feb;28(1):65-76.

13. Chen CC, Yi-Chou Wang A, Chen CT, Hsieh PC. Coadjuvant Treatment of Vasospasm in Ruptured Unsecured Cerebral Aneurysms with Aggressive Angioplasty, Intra-Arterial Nimodipine, and Aneurysm Embolization. World Neurosurg. 2018 Aug;116: e452e459.

14. Liu X, Zhao N, Zeng K, Xiao P, Sheng P, Luo X, Wang Y. Effects of nimodipine combined with betahistine on CRP and other inflammatory cytokines and vascular endothelial function in patients with hypertensive cerebral vasospasm. Clin Hemorheol Microcirc. 2020;75(3):279-289.

15. Kallel I, Hadrich B, Gargouri B, Chaabane A, Lassoued S, Gdoura R, Bayoudh A, Ben Messaoud E. Optimization of Cinnamon (Cinnamomum zeylanicum Blume) Essential Oil Extraction: Evaluation of Antioxidant and Antiproliferative Effects. Evid Based Complement Alternat Med. 2019 Dec 24; 2019:6498347.

16. Liu Z, Shi E, Ma F, Jiang K. An integrated biorefinery process for co-production of xylose and glucose using maleic acid as efficient catalyst. Bioresour Technol. 2021 Apr; 325:124698.

17. Zhang J, Hu J, He X, Meng Y, Chen G, Chen Z, Lü J, Li $P$. Effectiveness of Chinese herbal medicine for primary Raynaud's phenomenon: a systematic review and Metaanalysis of randomized controlled trials. J Tradit Chin Med. 2020 Aug;40(4):509-517.

18. Zhao J, Song Y, Wang H, Sun Y, Liu M, Lu C, Li Y, Wang $S$, Zhu $X$, Hai $W$, et al. High performance liquid chromatographic method for the determination of cinepazide maleate and its application to a pharmacokinetic study in rats. J Chromatogr B Analyt Technol Biomed Life Sci 2014; 957: 105-9. 